\title{
Influence of Grain Growth Inhibitors and Powder Size on the Properties of Ultrafine and Nanostructured Cemented Carbides Sintered in Hydrogen
}

\author{
Tamara Aleksandrov Fabijanić ${ }^{1}{ }^{*}$, Suzana Jakovljević ${ }^{1}$, Mladen Franz ${ }^{1}$ and Ivan Jeren ${ }^{2}$ \\ 1 Faculty of Mechanical Engineering and Naval Architecture, University of Zagreb, Ivana Lučića 5, \\ Zagreb 10000, Croatia; suzana.jakovljevic@fsb.hr (S.J.); mladen.franz@fsb.hr (M.F.) \\ 2 Alfa tim d.o.o., Čulinečka cesta 25, Zagreb 10040, Croatia; info@alfatim.hr \\ * Correspondence: tamara.aleksandrov@fsb.hr; Tel.: +385-1-6168-389
}

Academic Editor: Soran Birosca

Received: 8 July 2016; Accepted: 19 August 2016; Published: 24 August 2016

\begin{abstract}
The influence of grain growth inhibitors and powder size on the microstructure and mechanical properties of ultrafine and nanostructured cemented carbides was researched. Three different WC powders, with an addition of different type and content of grain growth inhibitors GGIs, VC and $\mathrm{Cr}_{3} \mathrm{C}_{2}$ and with $d_{\mathrm{BET}}$ grain sizes in the range from 95 to $150 \mathrm{~nm}$ were selected as starting powders. Four different mixtures with 6 and $9 \mathrm{wt}$ \% Co were prepared. The consolidated samples are characterized by different microstructural and mechanical properties with respect to the characteristics of starting powders. Increased sintering temperatures led to microstructural irregularities in the form of a discontinuous WC growth, carbide agglomerates and abnormal grain growth as a consequence of coalescence via grain boundary elimination. The addition of $0.45 \% \mathrm{Cr}_{3} \mathrm{C}_{2}$ contributed to microstructure homogeneity, reduced discontinuous and continuous grain growth, and increased Vickers hardness by approximately $70 \mathrm{HV}$ and fracture toughness by approximately $0.15 \mathrm{MN} / \mathrm{m}^{3 / 2}$. The reduction of the starting powder to a real nanosize of $95 \mathrm{~nm}$ resulted in lower densities, and significant hardness increase, with a simultaneously small increase in fracture toughness. The consolidation of real nanopowders $\left(d_{\mathrm{BET}}<100 \mathrm{~nm}\right)$ solely by conventional sintering in hydrogen without isostatic pressing is not preferred.
\end{abstract}

Keywords: ultrafine and nanostructured cemented carbides; grain growth inhibitors; powder size; sintering temperature; microstructural characteristics; mechanical properties

\section{Introduction}

Ultrafine cemented carbides with a $d_{\mathrm{WC}}$ grain size in the range from 0.2 to $0.500 \mu \mathrm{m}$ and nanostructured cemented carbides with a $d_{\text {WC }}$ grain size $<0.200 \mu \mathrm{m}$ are consolidated from ultrafine and nanosized WC starting powders, which are characterized by a big surface area and a very high sintering activity. One of the biggest challenges of sintering ultrafine and nanoscaled powders is the retention of a small WC grain size in the sintered product $[1,2]$. Numerous attempts to achieve nanostructured cemented carbides have failed due to high sintering activity of WC nanopowders [2,3]. For that reason, the nano- and near nanopowders with very low sintering activity with respect to the re-crystallization during liquid phase sintering were developed [2,4]. Furthermore, powders with small amounts of the so-called grain growth inhibitors, GGIs, homogeneously distributed in powder mixtures, were used. GGIs are dissolved in the Co matrix, segregated at WC-Co interfaces, thereby forming a solid solution with a lower melting temperature in the range from 1200 to $1250{ }^{\circ} \mathrm{C}$, saturated with GGIs [5,6]. The most common GGIs are vanadium carbide, $\mathrm{VC}$, chromium carbide, $\mathrm{Cr}_{3} \mathrm{C}_{2}$, tantalum carbide, $\mathrm{TaC}$, titanium carbide, $\mathrm{TiC}$ and niobium carbide $\mathrm{NbC}$, and due to their effectiveness, they can be ranked in the following order: $\mathrm{VC}>\mathrm{Cr}_{3} \mathrm{C}>\mathrm{NbC}>\mathrm{TaC}$ [6]. Their primary task is to preserve the particle 
size of starting powders in the sintered product, while at the same time influencing the properties of consolidated samples: decreasing density, increasing the value of hardness at room temperature, and also affecting toughness, hardness and creep resistance at elevated temperatures. The combination of $\mathrm{VC}-\mathrm{Cr}_{3} \mathrm{C}_{2}(\mathrm{TaC})$ proved the most effective due to its high solubility and mobility in the Co binder, which results in an optimal combination of hardness and toughness $[7,8]$. The process of grain growth in cemented carbides can be characterized as both continuous and discontinuous. Continuous growth is characterized by uniform growth of WC grains, while discontinuous growth characterizes growth of isolated WC grains or groups of WC grains, which grow faster and larger compared to the surrounding grains [8-10]. Both growth processes must be avoided in order to obtain satisfactory properties in the sintered products since mechanical properties of ultrafine and nanostructured cemented carbides are directly dependent on the developed microstructure: WC grain size, mean free path of Co and contiguity of WC grains $[2,10]$. Homogeneous microstructure without grain growth and homogeneous distribution of cobalt between carbide grains lead to optimal strength and improvements of hardness and toughness, while microstructural irregularities, like porosity and especially abnormal grain growth, result in poor transverse rupture strength [11]. Abnormal grain growth is characteristic of a system with faceted grains, which possess a singular interface and anisotropic surface energy.

Microstructure characteristics and mechanical properties of ultrafine and nanostructured cemented carbides were developed by conventional liquid phase sintering in hydrogen with respect to characteristics of the starting powder, and GGIs and the grain size of starting powders were researched. The influence of sintering temperature on microstructure and mechanical properties of sintered samples was analyzed. The research was performed to examine the possibility of consolidation by sintering in hydrogen atmosphere.

\section{Materials and Methods}

Near nano- and nanopowders were used as starting materials. According to the producers specification (HC Starck, Goslar, Germany) the powders have an average $d_{\mathrm{BET}}$ grain size in the range from 95 to $150 \mathrm{~nm}$ and a specific surface area (BET) in the range from 2.5 to $4.0 \mathrm{~m}^{2} / \mathrm{g}$. The selected WC powders had an addition of a different type and content of GGIs; VC and $\mathrm{Cr}_{3} \mathrm{C}_{2}$. The Co powder used was HMP Co, produced by Umicore (Bruxelles, Belgium). It has a $d_{\mathrm{BET}}$ of $210 \mathrm{~nm}$ and a specific surface area (BET) of $2.96 \mathrm{~m}^{2} / \mathrm{g}$. The characteristics of starting powders are presented in Table 1. Powders with different characteristics were selected in order to investigate the influence of grain size and GGIs on the behavior during sintering and the microstructure and mechanical properties of sintered samples.

Table 1. Characteristics of starting powders and mixtures.

\begin{tabular}{cccccc}
\hline Mixture & Powder & Grain Size, $\boldsymbol{d}_{\text {BET }}, \mathbf{n m}$ & Specific Surface, $\mathbf{~ m}^{\mathbf{2}} \mathbf{g}$ & GGI, wt. $\%$ & Co, $\%$ \\
\hline WC-9Co $/ 1$ & WC DN 2-5/1 & 150 & 2.57 & $0.26 \% \mathrm{VC}, 0.45 \% \mathrm{Cr}_{3} \mathrm{C}_{2}$ & 9 \\
WC-9Co $/ 2$ & WC DN 2-5/2 & 150 & 2.59 & $0.27 \% \mathrm{VC}$ & 9 \\
WC-6Co $/ 1$ & WC DN 2-5/1 & 150 & 2.57 & $0.26 \% \mathrm{VC}, 0.45 \% \mathrm{Cr}_{3} \mathrm{C}_{2}$ & 6 \\
WC-6Co $/ 2$ & WC DN 4-0 & 95 & 3.92 & $0.41 \% \mathrm{VC}, 0.80 \% \mathrm{Cr}_{3} \mathrm{C}_{2}$ & 6 \\
\hline
\end{tabular}

WC powders were mixed with 6 and 9 wt. \% Co and paraffin wax dissolved in hexane. WC-9Co mixtures had the same grain size of the starting WC powder, $150 \mathrm{~nm}$, but different GGIs in order to examine their influence on the properties of sintered samples. WC-6Co mixtures had the same type of grain growth inhibitors, $\mathrm{VC}+\mathrm{Cr}_{3} \mathrm{C}_{2}$, but different grain sizes of starting powders so as to analyze the influence of grain size on the properties of sintered samples. Mixing was carried out in a horizontal ball mill for the purpose of WC and Co homogenization. After subsequent drying of the slurry and granulation by sieving, the samples were compacted by uniaxial die pressing at room temperature on a hydraulic press. Different pressures were used for the compaction of green parts. The compaction pressure of $180 \mathrm{MPa}$ was applied for the mixtures with $150 \mathrm{~nm}$ starting powders while the compaction pressure of $250 \mathrm{MPa}$ was applied for the mixture with $95 \mathrm{~nm}$ starting powder. Dewaxing of green compacts was carried out in a separate cycle at $800{ }^{\circ} \mathrm{C}$. Before entering the sintering furnace, green 
compacts were placed on graphite trays and covered with aluminum oxide, $\mathrm{Al}_{2} \mathrm{O}_{3}$, which creates an atmosphere around the green compacts and separates each green compact. The samples were sintered by conventional liquid phase sintering in hydrogen. Sintering was performed at temperatures ranging from 1360 to $1420{ }^{\circ} \mathrm{C}$ in order to research the influence of sintering temperature on the microstructure and mechanical properties. Twelve samples overall were consolidated. The parameters of consolidation are presented in Table 2.

Table 2. Parameters of consolidation.

\begin{tabular}{|c|c|c|c|c|c|c|}
\hline Mixture & Sample & $\begin{array}{l}\text { Milling } \\
\text { Time, h }\end{array}$ & $\begin{array}{l}\text { Compaction } \\
\text { Pressure, MPa }\end{array}$ & $T_{\text {sint. } .}{ }^{\circ} \mathrm{C}$ & $\begin{array}{l}\text { Holding } \\
\text { Time, min }\end{array}$ & $\begin{array}{c}\text { Heating } \\
\text { Rate, }^{\circ} \mathrm{C} / \mathrm{min}\end{array}$ \\
\hline \multirow{3}{*}{ WC-9Co/1 } & $1-1$ & 72 & 180 & 1360 & 80 & 5 \\
\hline & $1-2$ & 72 & 180 & 1400 & 80 & 5 \\
\hline & $1-3$ & 72 & 180 & 1420 & 80 & 5 \\
\hline \multirow{3}{*}{ WC-9Co/2 } & $2-1$ & 72 & 180 & 1360 & 80 & 5 \\
\hline & $2-2$ & 72 & 180 & 1400 & 80 & 5 \\
\hline & $2-3$ & 72 & 180 & 1420 & 80 & 5 \\
\hline \multirow{3}{*}{ WC- $6 \mathrm{Co} / 1$} & 3-1 & 48 & 180 & 1360 & 80 & 5 \\
\hline & $3-2$ & 48 & 180 & 1400 & 80 & 5 \\
\hline & $3-3$ & 48 & 180 & 1420 & 80 & 5 \\
\hline \multirow{3}{*}{ WC-6Co/2 } & $4-1$ & 48 & 250 & 1360 & 80 & 5 \\
\hline & $4-2$ & 48 & 250 & 1400 & 80 & 5 \\
\hline & $4-3$ & 48 & 250 & 1420 & 80 & 5 \\
\hline
\end{tabular}

The density of the consolidated samples was determined using the Archimedes method, weighing the samples in air and in liquid according to EN ISO 3369:2006. The degree of porosity and uncombined carbon was determined by comparing the polished surface with photo micrographs from the standard (ISO 4505:1978). The analysis was performed using an optical microscope, a scanning electron microscope, or SEM (Tescan, Brno, Czech Republic), and a field emission electron microscope, or FESEM (Tescan, Brno, Czech Republic). The measurement of WC grain size was carried out by a conventional linear intercept method according to EN ISO 4499-2:2011 at very high magnification in order to isolate each individual grain at FESEM $(50000 \times, 60000 \times)$. During the microstructure analysis on the field emission scanning electron microscope, it was found that for the analysis of such small grain sizes it is not recommended to etch the surface. Due to very small grain size it was necessary to evaporate the sample surface with carbon. Vickers hardness HV30 and Palmqvist toughness were measured simultaneously according to ISO 28079:2009 on the basis of five indentations performed on each sample.

\section{Results and Discussion}

The characteristics of sintered samples are presented in Table 3.

Table 3. Characteristics of sintered samples.

\begin{tabular}{|c|c|c|c|c|c|c|c|c|}
\hline \multirow{2}{*}{ Mixture } & \multirow{2}{*}{ Sample } & \multicolumn{3}{|c|}{ Porosity } & \multirow{2}{*}{$\rho, \%$} & \multirow{2}{*}{$d_{\mathrm{WC}}, \mu \mathrm{m}$} & \multirow{2}{*}{ HV 30} & \multirow{2}{*}{$W_{\mathrm{k}}, \mathrm{MN} / \mathrm{m}^{3 / 2}$} \\
\hline & & A & B & $\mathrm{C}$ & & & & \\
\hline \multirow{3}{*}{ WC-9Co/1 } & $1-1$ & $\mathrm{~A}<02, \mathrm{~A} 02$ & B00, B02 & $\mathrm{C} 00$ & 99.2 & 0.213 & 1880.1 & 9.52 \\
\hline & $1-2$ & $\mathrm{~A}<02, \mathrm{~A} 02$ & B00, B02 & $\mathrm{C} 00$ & 99.6 & 0.249 & 1834.6 & 9.58 \\
\hline & $1-3$ & $\mathrm{~A}<02, \mathrm{~A} 02$ & B00, B02 & $\mathrm{CO0}$ & 99.5 & 0.261 & 1801.3 & 9.54 \\
\hline \multirow{3}{*}{ WC-9Co/2 } & $2-1$ & $\mathrm{~A}<02, \mathrm{~A} 02$ & B00, B02 & $\mathrm{C} 00$ & 99.2 & 0.251 & 1808.3 & 9.41 \\
\hline & $2-2$ & $\mathrm{~A}<02, \mathrm{~A} 02$ & B00, B02 & $\mathrm{CO0}$ & 99.4 & 0.265 & 1763.1 & 9.33 \\
\hline & $2-3$ & $\mathrm{~A}<02, \mathrm{~A} 02$ & B00, B02 & $\mathrm{CO0}$ & 99.5 & 0.316 & 1729.3 & 9.42 \\
\hline \multirow{3}{*}{ WC-6Co/1 } & $3-1$ & A04 & B00, B02 & $\mathrm{C} 00$ & 99.2 & 0.209 & 2041.1 & 9.05 \\
\hline & $3-2$ & A02 & B00, B02 & $\mathrm{CO0}$ & 99.0 & 0.235 & 2034.4 & 9.01 \\
\hline & $3-3$ & A02 & B00, B02 & $\mathrm{CO0}$ & 99.1 & 0.251 & 1988.2 & 9.10 \\
\hline \multirow{3}{*}{ WC-6Co/2 } & $4-1$ & A06 & B02, B04 & $\mathrm{C} 00$ & 98.6 & 0.166 & 2196.1 & 9.14 \\
\hline & $4-2$ & A04 & B02, B04 & $\mathrm{C} 00$ & 98.6 & 0.175 & 2164.9 & 9.12 \\
\hline & $4-3$ & A04 & B02, B04 & $\mathrm{C} 00$ & 98.9 & 0.195 & 2103.9 & 9.14 \\
\hline
\end{tabular}




\subsection{Density and Microstructural Characteristics}

Lower degree of porosity was achieved for samples with higher Co content. The degree of porosity of WC-9Co samples is predominantly A02, partially $\mathrm{A}<02$, predominantly B00, partially B02, without uncombined carbon or $\eta$-phase. The degree of porosity of WC-6Co samples ranges from A02 to A06, predominantly B02, without uncombined carbon or $\eta$-phase. Additionally, small cracks occurred on several samples resulting from one of the following technological operations: milling, waxing or granulation. Achieved densities of all samples are lower than the theoretical density. Densities measured for WC-9Co samples range from $99.2 \%$ to $99.6 \%$ of the theoretical density and the maximal density is obtained for sample 1-2 sintered at $1400^{\circ} \mathrm{C}$. Densities measured for WC-6Co samples are lower compared to the WC-9Co mixture and range from $98.6 \%$ to $99.2 \%$. Even with higher compaction pressures used during uniaxial die pressing, the high degree of porosity with pore sizes larger than $2 \mu \mathrm{m}$ was obtained for the WC-6Co/2 mixture (Figure 1).

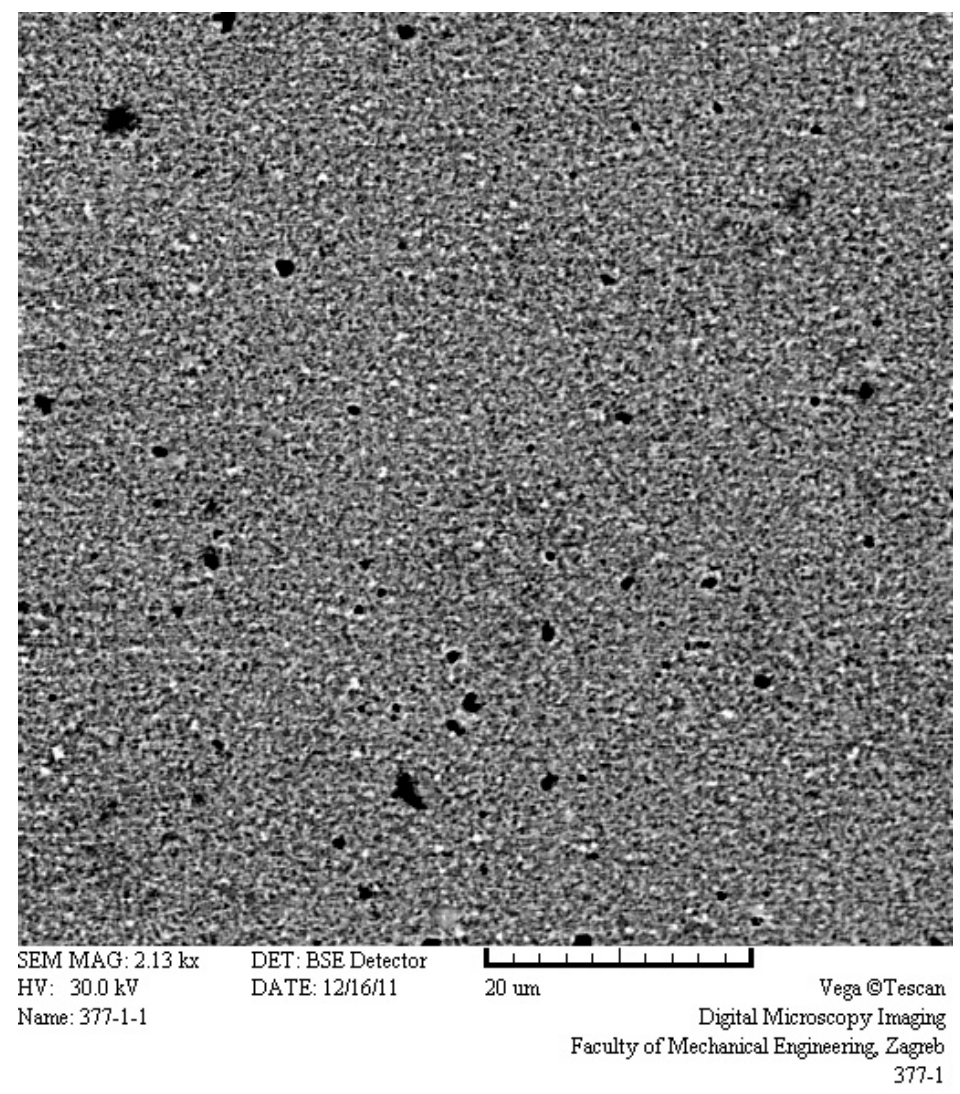

Figure 1. Porosity of sample 4-2.

The influence of sintering temperature on the density of consolidated samples is presented graphically in Figure 2.

WC-9Co mixtures had the same trend, and they recorded an increase in density with increasing sintering temperature. The highest density of WC-9Co mixtures was obtained at $1400{ }^{\circ} \mathrm{C}$. The difference between the measured density with respect to sintering temperature is small and amounts to only $0.3 \%$ to $0.4 \%$, which may be due to compaction. The maximal density achieved for WC-9Co samples is $99.6 \%$ of the theoretical density, which is a highly relevant result for the process of sintering in hydrogen atmosphere. Sun published that the density of WC-Co samples with a grain sizes of approximately $0.250 \mu \mathrm{m}$ is significantly influenced by $\mathrm{Cr}_{3} \mathrm{C}_{2}$ content. The increase of $0.4 \mathrm{wt}$. \% $\mathrm{Cr}_{3} \mathrm{C}_{2}$ content considerably reduces the density; when the $\mathrm{Cr}_{3} \mathrm{C}_{2}$ content is small the change is slight [8]. The addition of $0.45 \% \mathrm{Cr}_{3} \mathrm{C}_{2}$ in WC-9Co/1 did not lead to lower density compared to WC-9Co/2, which has 
only $0.27 \%$ VC. WC-6Co mixtures recorded lower values of measured density compared to WC-9Co mixtures. The density of WC-6Co/1 ranges from $99.0 \%$ to $99.2 \%$ of the theoretical density. The maximal value is achieved at the lowest sintering temperature, meaning that full densification was achieved. The density decreases with increasing temperature, which can be explained by the fact that the samples were compacted by uniaxial die pressing, the lack whereof is density non-uniformity. The density of WC-6Co/2 is increasing with increasing sintering temperature. WC-6Co/2 has a GGIs content two times higher compared to WC-6Co/1, which may indicate that GGIs influenced the achieved densities. In general, it can be concluded that the mixtures with lower Co content achieved lower densities. The achieved densities are quite low compared to densities which could be achieved by sinter-HIP process.

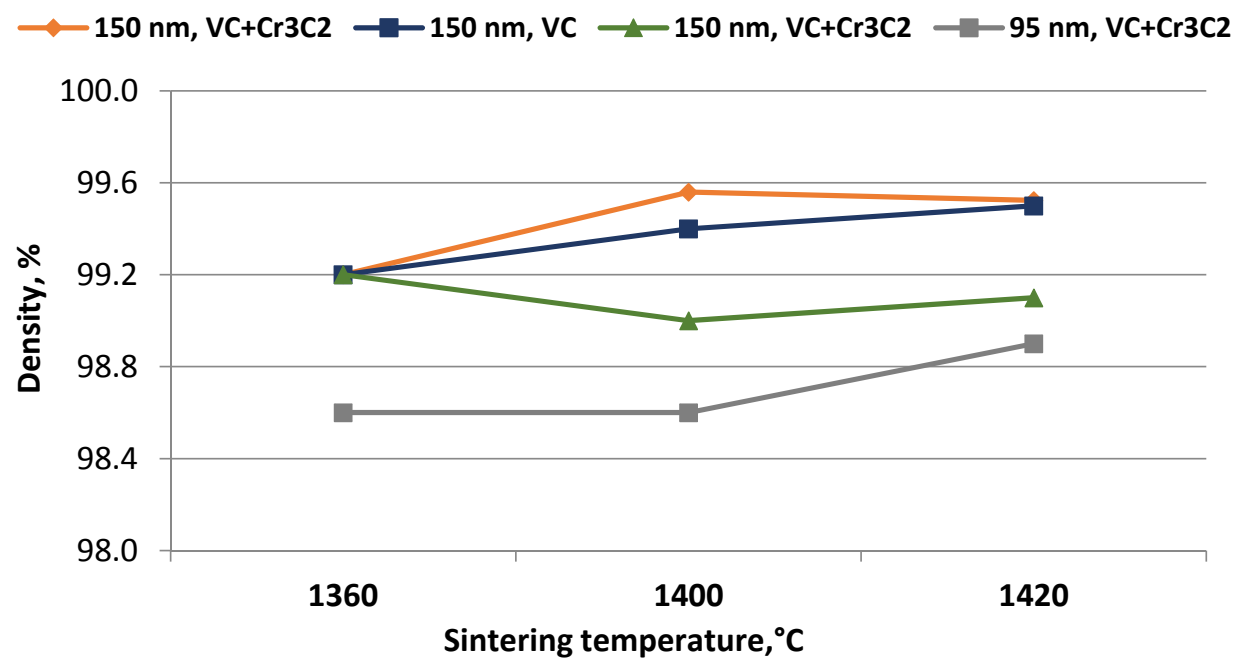

Figure 2. Correlation of densities and sintering temperature.

The size of the starting powders is almost retained at the lowest sintering temperatures. Accordingly, some of the consolidated cemented carbides can be classified as nanostructured WC-Co $\left(d_{\mathrm{WC}}<0.200 \mu \mathrm{m}\right)$ where $d_{\mathrm{WC}}$ represents the mean WC grain size determined by linear intercept method. The microstructure of samples obtained by SEM at the lowest sintering temperature, $1360{ }^{\circ} \mathrm{C}$, is presented in Figure 3.

The microstructures are fine, with uniform grain size distribution, homogeneous and without abnormal grain growth at lower sintering temperatures. Nevertheless, a difference in microstructure between samples was noted. The smallest grain size of $d_{\mathrm{WC}}=0.166 \mathrm{~nm}$ was measured for sample 4-1 (Figure 3d). The most homogenous microstructure was noted for sample 3-1 (Figure 3c). The biggest grain size of $d_{\mathrm{WC}}=0.251$ was measured for sample 2-1 (Figure 3b), where a discontinuous growth of single carbides in the microstructure, even at the lowest sintering temperature, was noted. Microstructural defects in the form of discontinuous growth of individual WC grains and abnormal grain growth of carbide agglomerates occurred, especially for mixture 2, at higher sintering temperatures. Discontinuous growth of individual WC grains, which grows more dramatically, faster and larger compared to surrounding grains, and the grouping of carbides are presented in Figure 4.

In general, such behavior represents a classical theory called Ostwald ripening (solution/ re-precipitation process), where large WC grains grow at the expense of small WC grains that dissolve in Co binder spread around the grains. This process is called coarsening of WC grains. Still, scientists have found that Ostwald ripening/coarsening is not sufficient to explain grain growth in nanostructured cemented carbides with lower Co content where WC grains are not surrounded by Co binder but with one another. A new mechanism suggested by numerous scientists $[6,11,12]$ is coalescence. Coalescence is the process by which two or more faceted WC grains merge during contact and consequently form a larger grain by diffusion and grain rotation thought rapid mass 
transport [11]. This mechanism can take place only if the grains are already bonded to each other, with a grain boundary and preferred orientations, as presented in Figure 5. Further holding at the sintering temperature would result in grain boundaries movement, the consequence of which would be further grain growth. Another reason for discontinuous grain growth can be chemical inhomogenities (i.e., $\mathrm{S}$, $\mathrm{Ca}, \mathrm{C}$, etc.) and areas without GGIs.

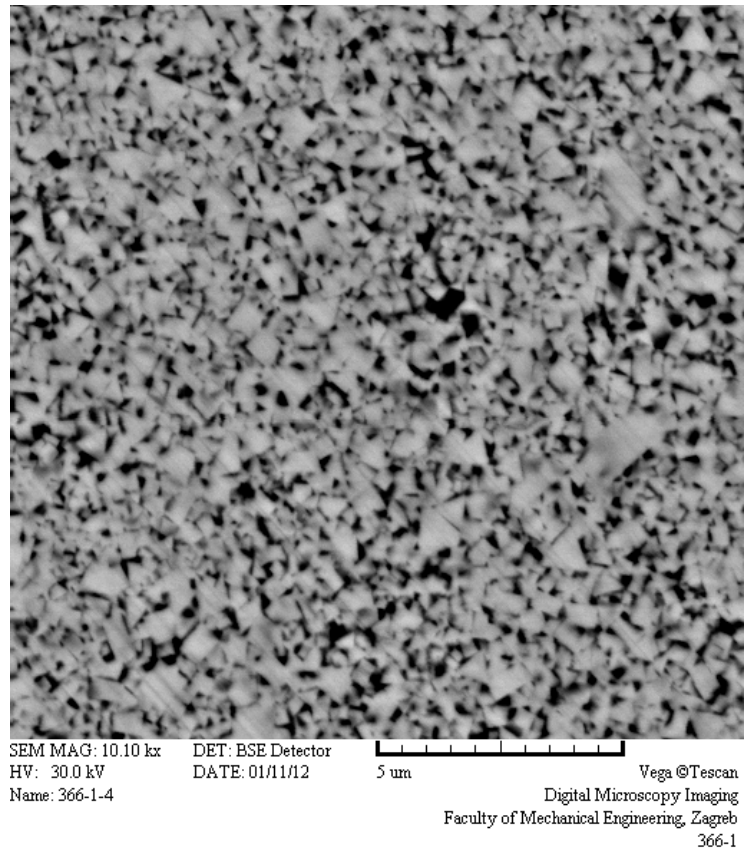

(a)

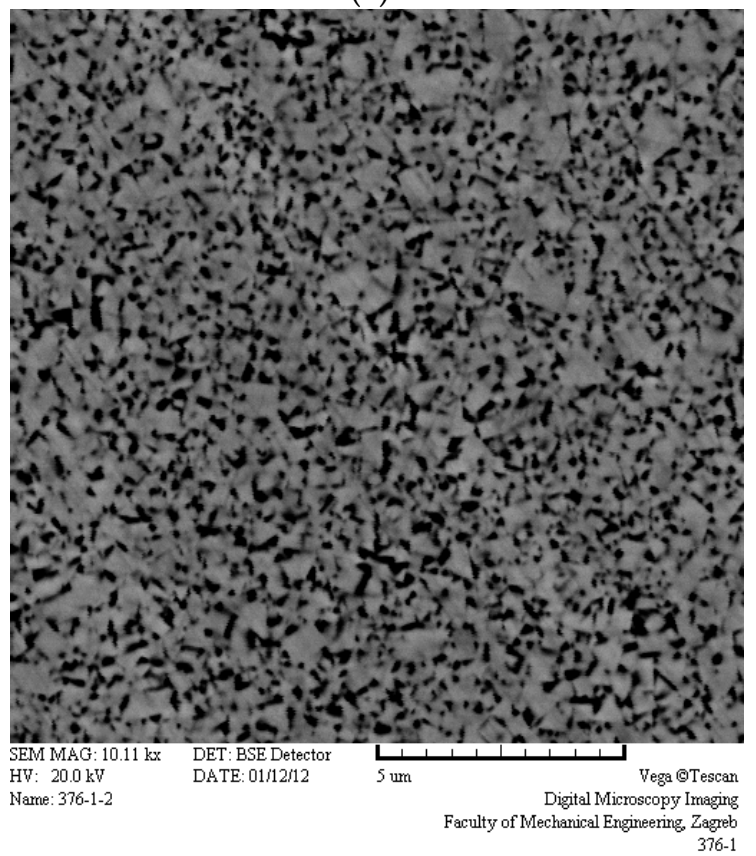

(c)

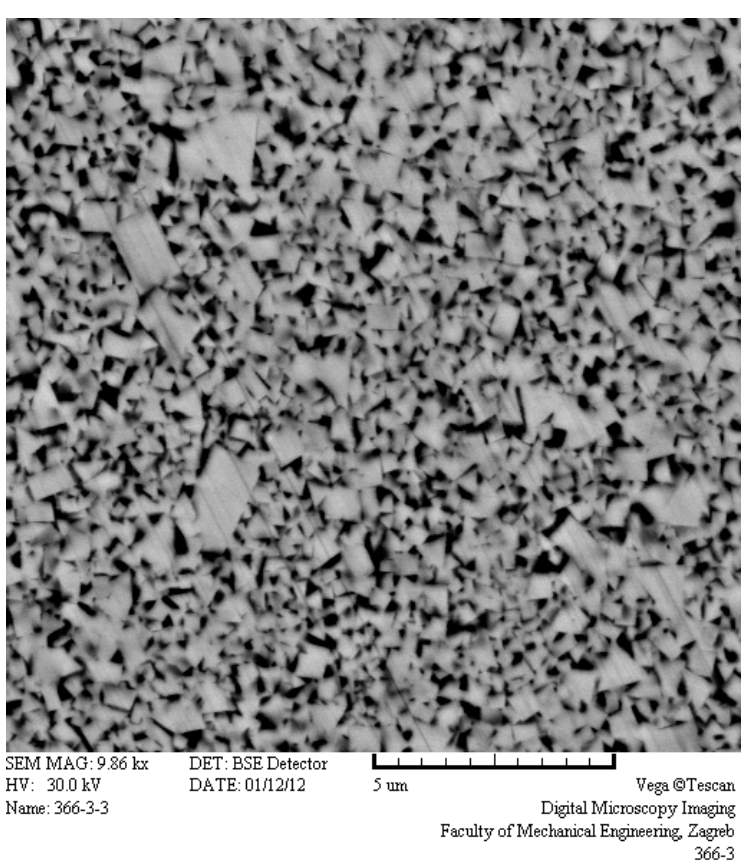

(b)

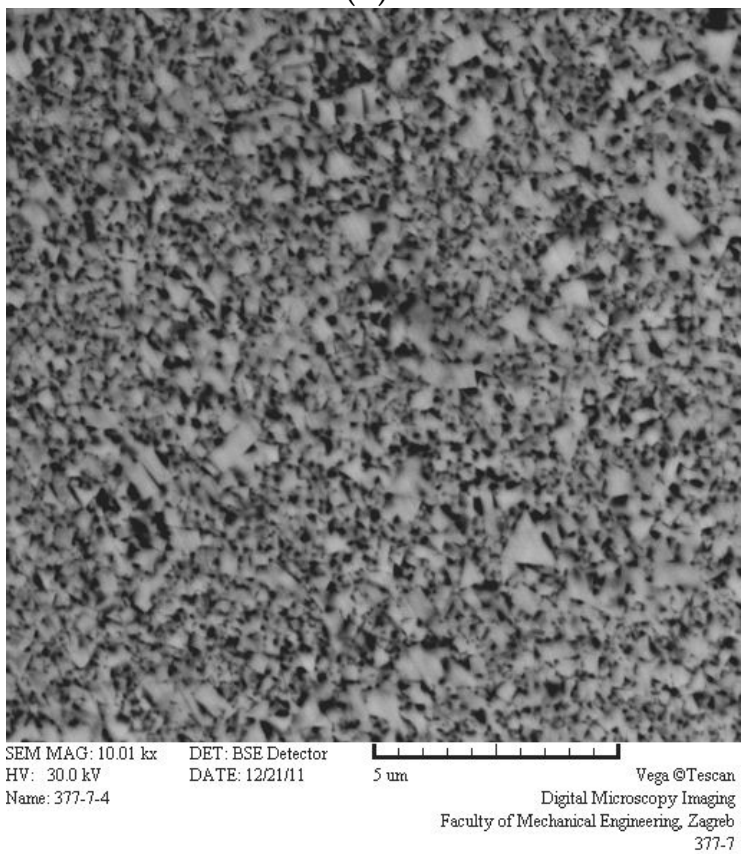

(d)

Figure 3. Microstructures of ultrafine and nanostructured cemented carbides. (a) Sample 1-1; (b) sample 2-1; (c) sample 3-1; (d) sample 4-1. 


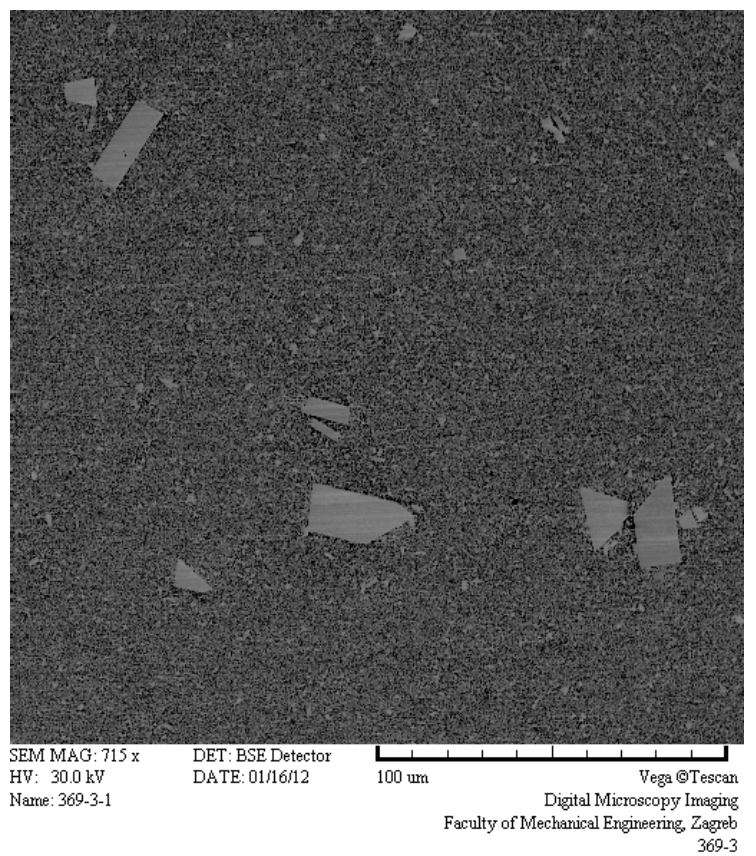

(a)

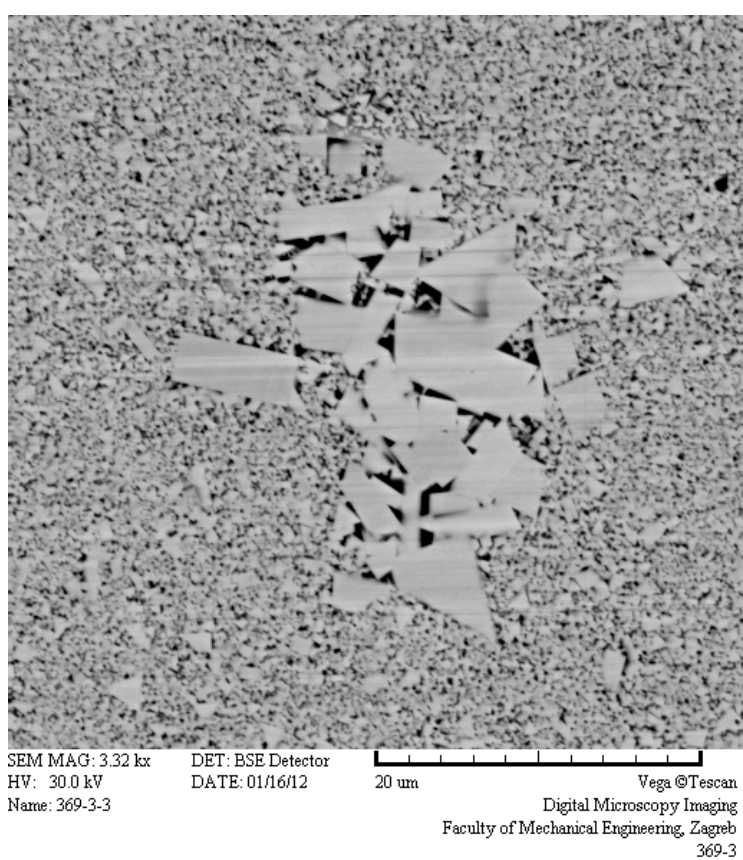

(b)

Figure 4. Microstructural irregularities. (a) Discontinuous growth of individual grains on sample 2-3; (b) abnormal grain growth of carbide agglomerates on sample 2-3.

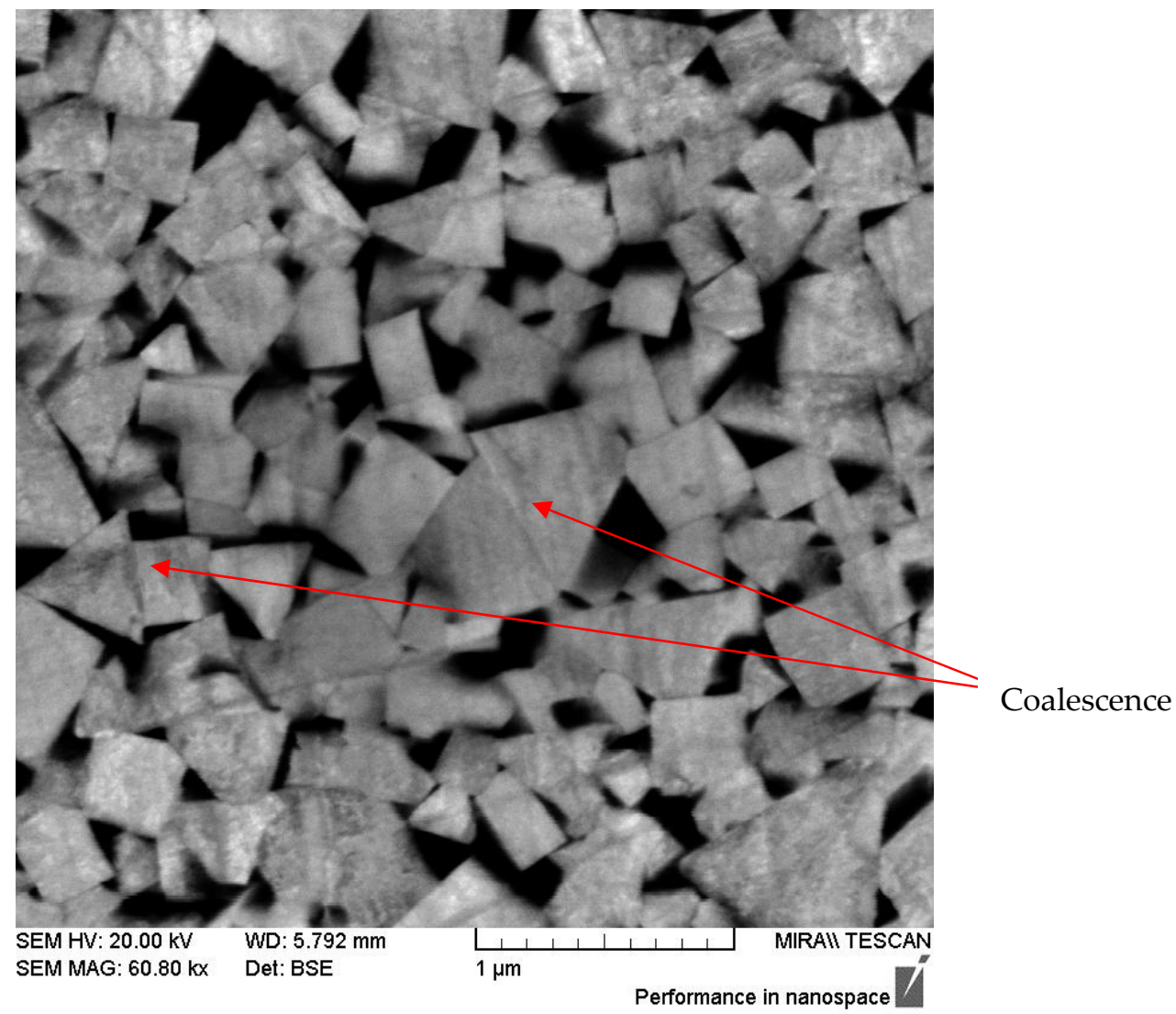

Figure 5. Microstructure with coalescence.

The influence of sintering temperature on WC grain size is illustrated in Figure 6. 


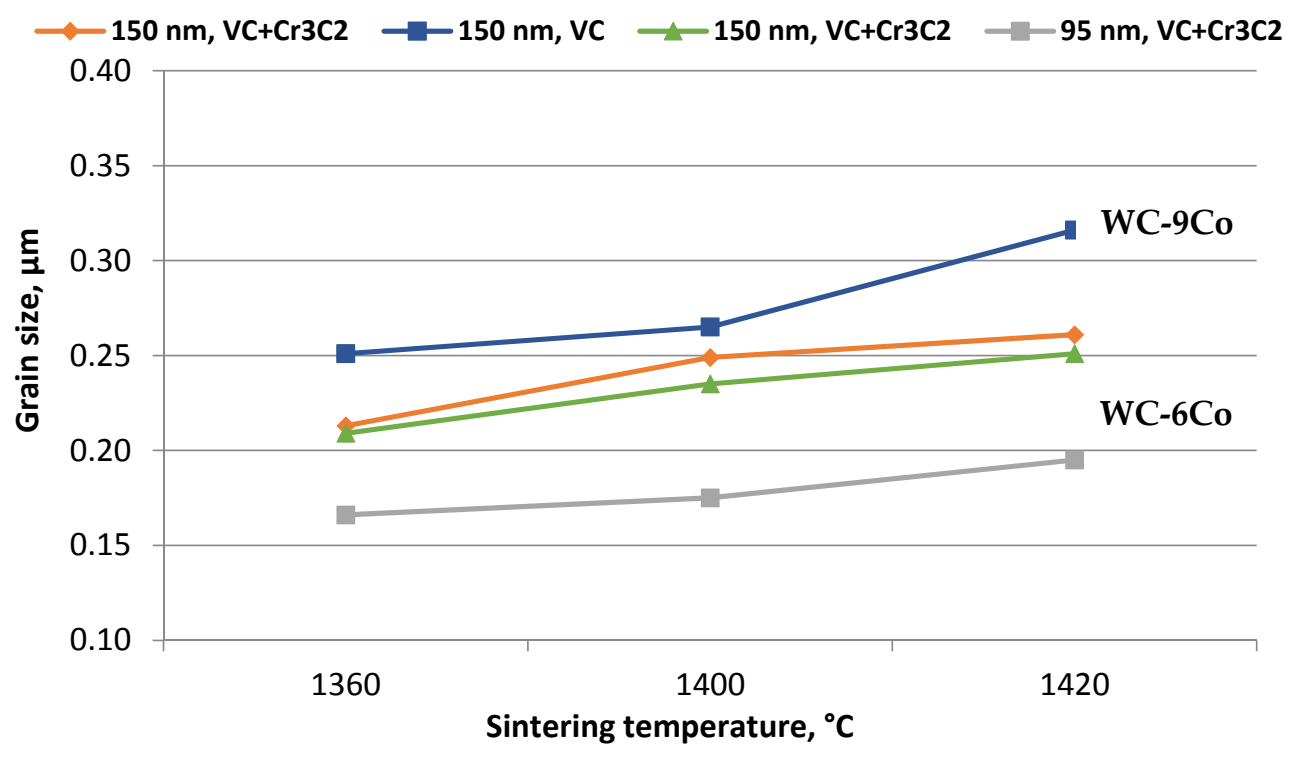

Figure 6. Correlation of WC grain size and sintering temperature.

The sintering temperature contributed significantly to microstructural characteristics of consolidated cemented carbides. The size of WC grains increases with increasing sintering temperatures for all mixtures. The largest increase was recorded for WC-9Co/2; $150 \mathrm{~nm}$ and the addition of VC. At the lowest sintering temperature, the measured WC grain size is $0.251 \mu \mathrm{m}$, which is an increase of $0.1 \mu \mathrm{m}$ compared to the starting powder. It is important to note that microstructural analysis showed the existence of abnormal grain growth and grouping of carbides, especially at the highest sintering temperatures. It follows that the addition of $0.27 \%$ VC as GGI is too low to retain grain size of the starting powder in the sintered samples. Mixture WC-9Co/1, $150 \mathrm{~nm}$ with the addition of $\mathrm{Cr}_{3} \mathrm{C}_{2}$ and $\mathrm{VC}$, retains a smaller grain size in relation to the starting powder. The grain growth of WC-9Co/1 in general is slightly higher compared to WC-6Co/1 consolidated from the same starting powder but with lower Co content. Co content contributed to the recrystallization and grain growth of near nano- and nanostructured cemented carbides sintered in hydrogen, confirming the role of Co in grain growth, already researched by various scientists [11,13-15]. The smallest grain sizes were measured for WC-6Co/2, $95 \mathrm{~nm}$ and the addition of $\mathrm{Cr}_{3} \mathrm{C}_{2}$ and VC, but in higher content compared to other mixtures. The finer the grain size of the starting powder, the smaller the final grain size. Yet at the highest sintering temperature, the grouping of the carbides and grain growth occurred for all samples. WC grain growth is dependent on the type and amount of GGIs and the grain size of the starting powder.

\subsection{Mechanical Properties}

The characteristics of starting powders, sintering temperature and achieved microstructure influenced the mechanical properties of consolidated samples. A graphical representation of the correlation between Vickers hardness and sintering temperature is presented in Figure 7.

The measured hardness is substantially influenced by sintering temperature and a consequently developed microstructure. Maximal hardness values were measured at the lowest sintering temperature, where the most uniform, homogenous microstructure was achieved for all mixtures. Furthermore, the characteristics of starting powders, GGIs and WC grain size of the starting powder influenced the measured hardness. The highest hardness was measured for WC-6Co/2 with the smallest grain size of the starting powder and the highest content of GGIs. The lowest hardness was achieved for WC-9Co/2 with the lowest content of GGIs and the biggest grain size. The correlation of Palmqvist toughness and sintering temperatures is presented in Figures 8 and 9. 


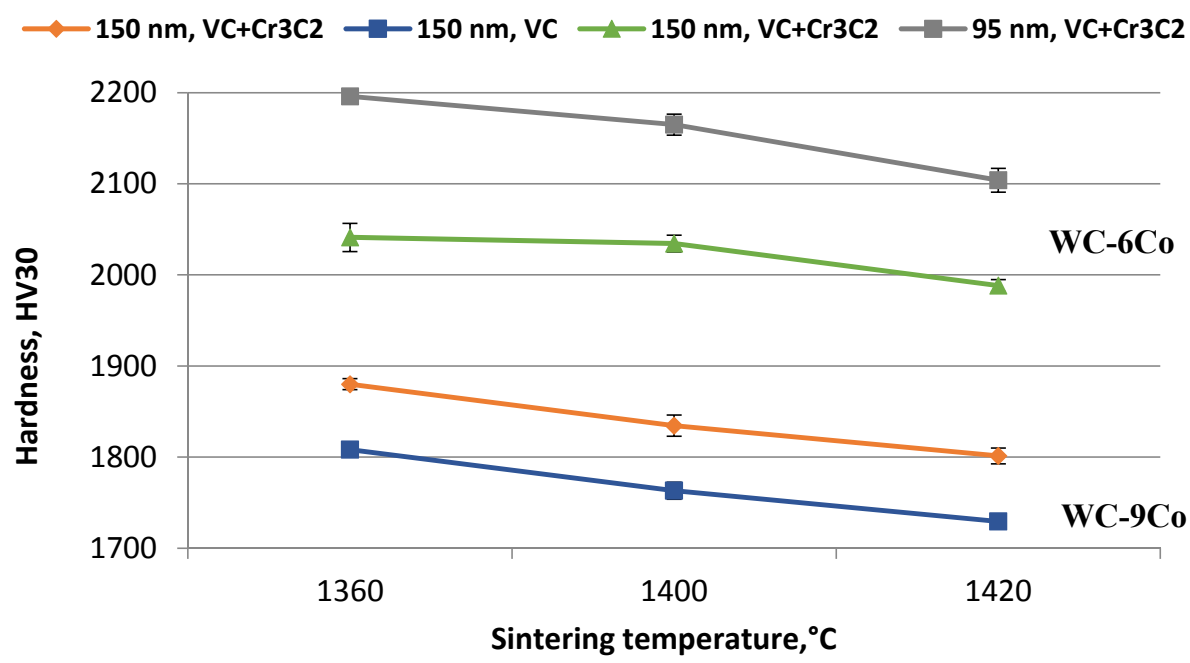

Figure 7. Correlation of Vickers hardness and $T_{\text {sint. }}$ for all mixtures.

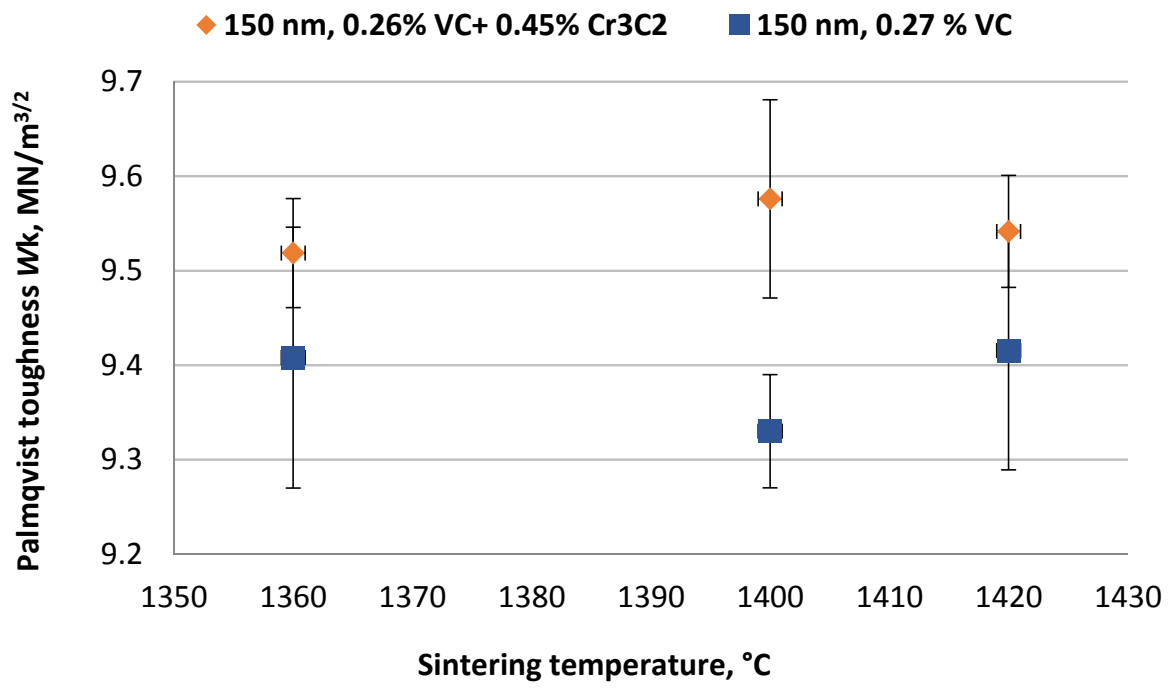

Figure 8. Correlation of Palmqvist toughness and $T_{\text {sint. }}$ for WC-9Co mixtures.

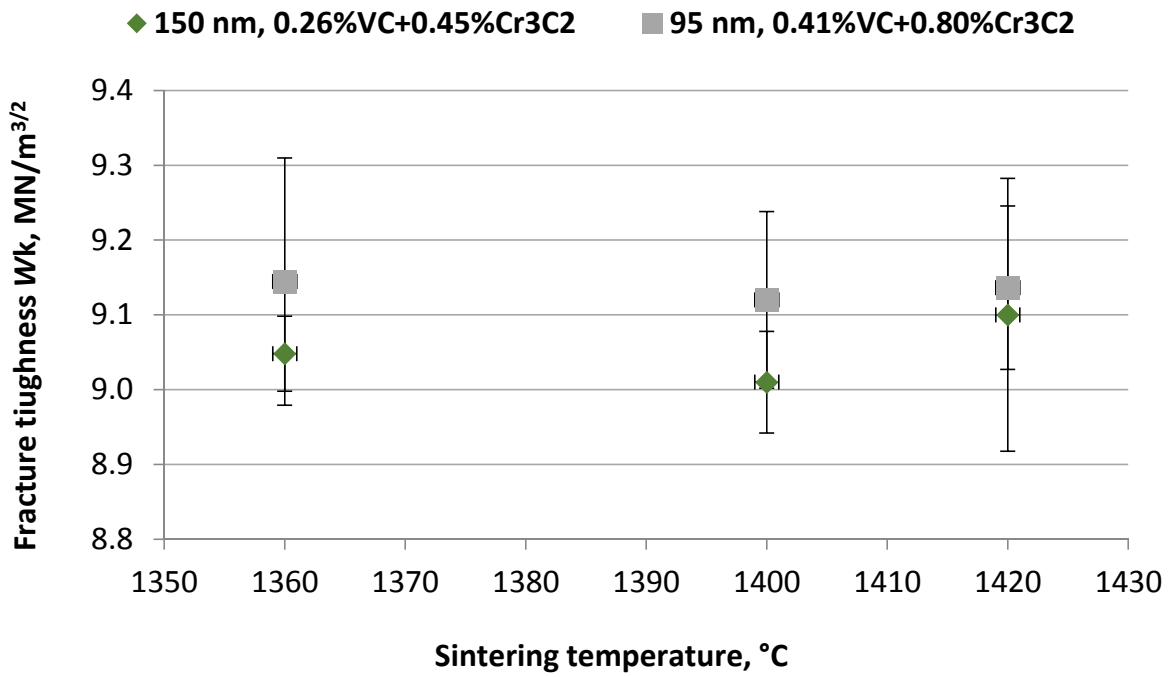

Figure 9. Correlation of Palmqvist toughness and $T_{\text {sint. }}$ for WC-6Co mixtures. 
The measured Palmqvist toughness of WC-9Co mixtures is the same for all three sintering temperatures. The maximal value of $9.57 \mathrm{MN} / \mathrm{m}^{3 / 2}$ was measured for sample $1-2$ sintered at $1400^{\circ} \mathrm{C}$. Higher values were achieved for WC-9Co/1, $150 \mathrm{~nm}$ and $\mathrm{VC}$ and $\mathrm{Cr}_{3} \mathrm{C}_{2}$. Palmqvist toughness does not change with the increase in sintering temperature, which causes microstructural irregularities and consequently a change in hardness.

The sintering temperature did not influence the Palmqvist toughness of WC-6Co mixtures. A slightly higher Palmqvist toughness was achieved for the WC-6Co/2 mixture with a smaller grain size of the starting powder and a higher content of GGI. The correlation of Palmqvist toughness versus Vickers hardness for WC-9Co mixtures with respect to GGIs and the correlation of Palmqvist toughness and Vickers hardness for WC-6Co mixtures with respect to $d_{\mathrm{BET}}$ of starting powders and GGI content are presented in Figures 10 and 11.

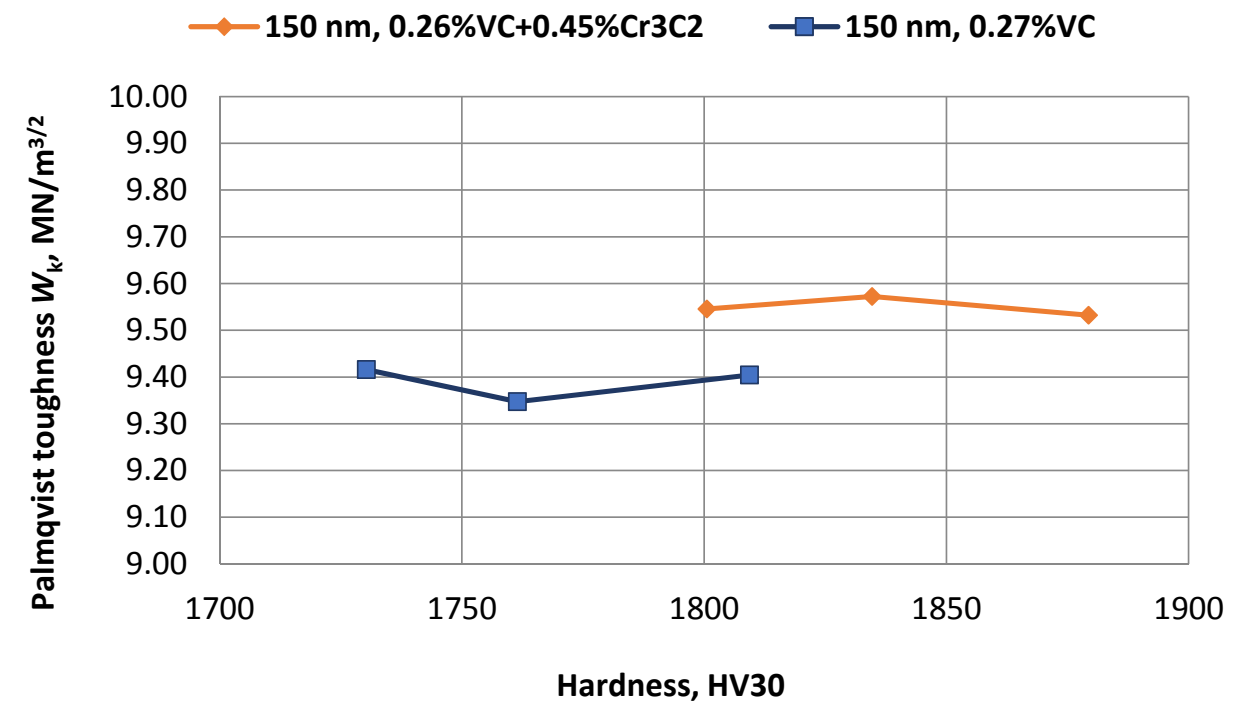

Figure 10. Palmqvist toughness versus hardness for WC-9Co mixtures with respect to GGIs.

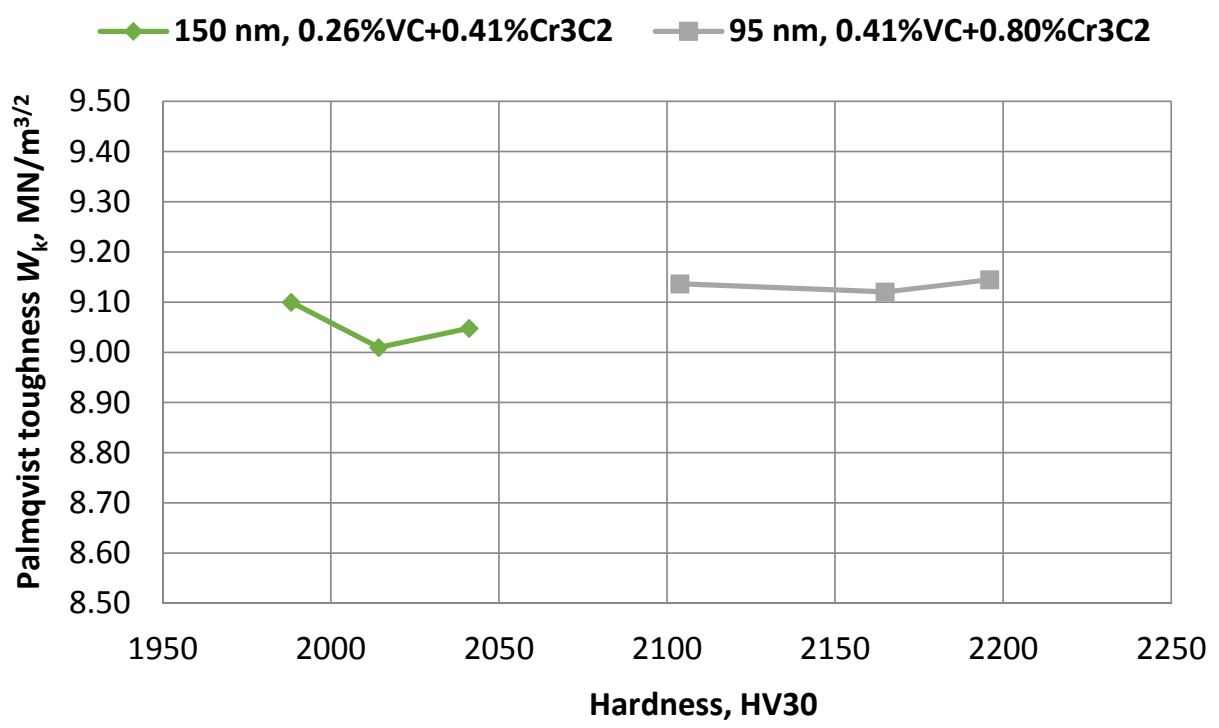

Figure 11. Palmqvist toughness versus hardness for WC-6Co mixtures with respect to $d_{\mathrm{BET}}$ of starting powders and GGI content.

A significant difference in measured Vickers hardness was noted comparing WC-9Co mixtures with the same size starting powder, $150 \mathrm{~nm}$, but different GGIs. The addition of $0.45 \% \mathrm{Cr}_{3} \mathrm{C}_{2}$ 
increased the Vickers hardness by approximately $70 \mathrm{HV}$ and the fracture toughness by approximately $0.15 \mathrm{MN} / \mathrm{m}^{3 / 2}$ for all sintering temperatures and reduced the hardness decrease with increasing temperature. The correlation between Palmqvist toughness and Vickers hardness is not linear and does not change with the change in hardness.

A significant difference in the measured Vickers hardness was noted comparing WC-6Co mixtures with the same type of GGIs but a different $d_{\mathrm{BET}}$ grain size and a specific surface area (BET) of starting WC powders. The reduction in grain size from $150 \mathrm{~nm}$ to a real nanosize of $95 \mathrm{~nm}$ resulted in significant hardness increase $(150 \mathrm{HV})$ for all sintering temperatures. Nonetheless, in spite of a significant increase in hardness, the measured value of fracture toughness is only slightly higher and more uniform. Fracture toughness stability is not typical of the majority of materials, including conventional WC-Co cemented carbides. It is important to note that GGIs also contributed to this behavior. Grain size reduction may result in significant hardness increase, while there is no decrease in toughness.

\section{Conclusions}

The following conclusions can be drawn from the conducted research:

(1) In general, higher densities are achieved with higher Co content and greater grain size of the starting powder. Achieved densities of WC-9Co mixtures are close to theoretical densities. Comparing two WC-9Co mixtures with a $150 \mathrm{~nm}$ starting powder with different GGIs, it can be concluded that the addition of $0.45 \mathrm{wt} . \% \mathrm{Cr}_{3} \mathrm{C}_{2}$ did not lead to lower density. The achieved densities are lower compared to densities which would be achieved with a sinter-HIP process or by sintering in vacuum.

(2) The behavior of the $95 \mathrm{~nm}$ starting powder, classified as real nanopowder, is completely different compared to the $150 \mathrm{~nm}$ staring powder; higher pressures are needed for the consolidation of green parts. Even with higher pressures, a microstructure with a lower densities was obtained. The consolidation of real nanopowders only by sintering in hydrogen without isostatic pressing is not recommended. Sinter-HIP process would be more suitable for the consolidation of real nano powders.

(3) The sintering temperature significantly impacted the microstructure of ultrafine and nanostructured cemented carbides. Increased sintering temperatures lead to microstructural irregularities in a form of discontinuous WC growth, carbide agglomerates and abnormal grain growth, as well as significant hardness decrease, especially for the mixture with only VC as GGIs. The lowest sintering temperature resulted in a fine-grained homogenous microstructure. It is preferred to use a higher amount of GGIs in case of sintering in hydrogen atmosphere.

(4) The characteristic of the starting powder (grain size and amount, as well as type of GGI) significantly influenced the microstructure and mechanical properties. The addition of $0.45 \%$ $\mathrm{Cr}_{3} \mathrm{C}_{2}$ contributed to microstructure homogeneity, reduced discontinuous and continuous grain growth, increased Vickers hardness by approximately $70 \mathrm{HV}$ and fractured toughness by approximately $0.15 \mathrm{MN} / \mathrm{m}^{3 / 2}$. The reduction of the starting powder grain size from $150 \mathrm{~nm}$ to a real nanosize of $95 \mathrm{~nm}$ resulted in a significant hardness increase with a simultaneous small increase in fracture toughness.

(5) Fracture toughness is not influenced by microstructural irregularities or the change in Vickers hardness.

Author Contributions: Tamara Aleksandrov Fabijanić performed density, grain size, hardness and fracture toughness measurements, analyzed the data and wrote the paper; Suzana Jakovljević performed microstructural analysis with a scanning electron microscope; Mladen Franz analyzed the data; and Ivan Jeren consolidated the samples.

Conflicts of Interest: The authors declare no conflict of interest. 


\section{References}

1. Richter, V.; Poetschke, J.; Holke, R.; Michaelis, A. Nanoscaled Cemented carbides—Fiction or Reality? In Proceedings of the 18th International Plansee Seminar, Reutte, Austria, 3-7 June 2013.

2. Fabijanić, T.A.; Alar, Ž.; Ćorić, D. Influence of consolidation process and sintering temperature on microstructure and mechanical properties of near nano and nano-structured WC-Co cemented carbides. Int. J. Refract. Met. Hard Mater. 2016, 54, 82-89. [CrossRef]

3. Al-Aqeeli, N.; Saheb, N.; Laoui, T.; Mohammad, K. The Synthesis of Nanostructured WC-Based Cemented carbides Using Mechanical Alloying and Their Direct Consolidation. J. Nanomater. 2014. [CrossRef]

4. Weidow, J.; Norgren, S.; Andren, H. Effect of V, Cr and Mn Additions on the Microstructure of WC-Co. Int. J. Refract. Met. Hard Mater. 2009, 27, 817-822. [CrossRef]

5. Poetschke, J.; Richter, V.; Holke, R. Influence and effectivity of $\mathrm{VC}$ and $\mathrm{Cr}_{3} \mathrm{C}_{2}$ grain growth inhibitors on sintering if binderless tungsten carbide. Int. J. Refract. Met. Hard Mater. 2012, 31, 218-223. [CrossRef]

6. Fang, Z.Z.; Wang, X.; Ryu, T.; Hwang, K.S.; Sohn, H.Y. Synthesis, sintering, and mechanical properties of nanocrystalline cemented tungsten carbide-A review. Int. J. Refract. Met. Hard Mater. 2009, 27, 288-299. [CrossRef]

7. Gille, G.; Szesny, B.; Dreyer, K.; van den Berg, H.; Schmidt, J.; Gestrich, T.; Leitner, G. Submicron and ultrafine grained cemented carbides for microdrills and metal cutting inserts. Int. J. Refract. Met. Hard Mater. 2002, 20, 3-22. [CrossRef]

8. Sun, L.; Jia, C.; Cao, R.; Lin, C. Effects of $\mathrm{Cr}_{3} \mathrm{C}_{2}$ additions on the densification, grain growth and properties of ultrafine WC-11Co composites by spark plasma sintering. Int. J. Refract. Met. Hard Mater. 2008, 26, 357-361. [CrossRef]

9. Kishino, J.; Nomura, H.; Shin, S.-G.; Matsubara, H.; Tanase, T. Computational study on grain growth in cemented carbides. In Proceedings of the 15th Internationla Plansee Seminar, Reutte, Austria, May 2001; Kneringer, G., Rodhammer, P., Wildner, H., Eds.; Plansee AG: Reutte, Austria, 2001; Volume 2.

10. Sivaprahasam, D.; Chandrasekar, S.B.; Sundaresan, R. Microstructure and mechanical properties of nanocrystalline WC-12Co consolidated by spark plasma sintering. Int. J. Refract. Met. Hard Mater. 2007, 25, 144-152. [CrossRef]

11. Mannesson, K. WC Grain Growth during Sintering of Cemented Carbides. Ph.D. Thesis, KTH Industrial Engineering and Management, Stockholm, Sweden, April 2011.

12. Wang, X.; Fang, Z.Z.; Sohn, H.Y. Grain growth during earla stage of sintering of nanosized WC-Co powder. Int. J. Refract. Met. Hard Mater. 2008, 26, 232-241. [CrossRef]

13. Mannesson, K.; Elfwing, M.; Kusoffsky, A.; Norgeren, S.; Agren, J. Analysis of WC grain growth during sintering using electron backscatter diffraction and image analysis. Int. J. Refract. Met. Hard Mater. 2008, 26, 449-455. [CrossRef]

14. Da Silva, A.G.P.; Schubert, W.D.; Lux, B. The Role of the Binder Phase in the WC-Co Sintering. Mat. Res. 2001. [CrossRef]

15. Breval, E.; Cheng, J.P.; Agrawal, D.K.; Gigl, P.; Dennis, M.; Roy, R.; Papworthc, A.J. Comparison between microwave and conventional sintering of WC/Co composites. Mater. Sci. Eng. A 2005, 391, 285-295. [CrossRef]

(C) 2016 by the authors; licensee MDPI, Basel, Switzerland. This article is an open access article distributed under the terms and conditions of the Creative Commons Attribution (CC-BY) license (http://creativecommons.org/licenses/by/4.0/). 